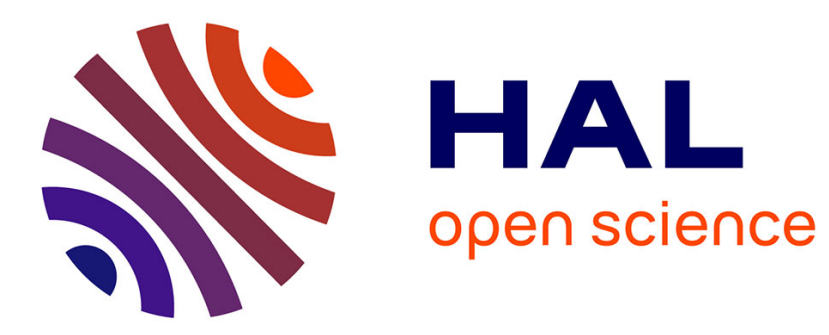

\title{
In vitro ultrasonic and mechanic characterization of the modulus of elasticity of children cortical bone
} Jean-Philippe Berteau, Martine Pithioux, Cécile Baron, Launay Franck, Patrick Chabrand, Philippe Lasaygues

\section{- To cite this version:}

Jean-Philippe Berteau, Martine Pithioux, Cécile Baron, Launay Franck, Patrick Chabrand, et al.. In vitro ultrasonic and mechanic characterization of the modulus of elasticity of children cortical bone. Ultrasonics, 2014, 54 (5), pp.1270-1276. 10.1016/j.ultras.2013.09.014 . hal-00937888

\section{HAL Id: hal-00937888 \\ https://hal.science/hal-00937888}

Submitted on 28 Jan 2014

HAL is a multi-disciplinary open access archive for the deposit and dissemination of scientific research documents, whether they are published or not. The documents may come from teaching and research institutions in France or abroad, or from public or private research centers.
L'archive ouverte pluridisciplinaire HAL, est destinée au dépôt et à la diffusion de documents scientifiques de niveau recherche, publiés ou non, émanant des établissements d'enseignement et de recherche français ou étrangers, des laboratoires publics ou privés. 
Ultrasonics

Elsevier Editorial system(tm) for

Manuscript Draft

Manuscript Number:

Title: In vitro ultrasonic and mechanic characterization of the modulus of elasticity of children cortical bone

Article Type: Special Issue: Bone

Section/Category: Materials characterization (A.G. Every)

Keywords: Ultrasonic wave velocities -Elastic properties-PediatricsCortical bone

Corresponding Author: Dr Martine pithioux, PhD

Corresponding Author's Institution: Aix Marseille Université

First Author: Jean-Philippe Berteau, PhD

Order of Authors: Jean-Philippe Berteau, PhD; Cécile Baron, PhD; Martine pithioux, PhD; Franck Launay, PU, PH; Patrick CHABRAND, PU; Philippe Lasaygues, PhD

Abstract: The assessment of elastic properties in children's cortical bone is a major challenge for biomechanical engineering community, more widely for health care professionals. Even with classical clinical modalities such as X-ray tomography, MRI, and/or echography, inappropriate diagnosis can result from the lack of reference values for children bone. This study provides values for elastic properties of cortical bone in children using ultrasonic and mechanical measurements, and compares them with adult values. 17 fibula samples from 8 children (4 to 16 years old, mean age 10 years old +/-4.5) were compared to 16 fibulae samples from elderly adults (more than 75 years old). First, the dynamic modulus of elasticity (MOEdyn) and Poisson's ratio (v) are evaluated via an ultrasonic method. Second, the static modulus of elasticity (MOEsta) is estimated from a 3-point microbending test. The mean values of longitudinal and transverse wave velocities measured at 10 $\mathrm{MHz}$ for the children's samples are respectively $3.2 \mathrm{~mm} / \mu \mathrm{s}(+/-0.5)$ and $1.8 \mathrm{~mm} / \mu \mathrm{s}(+/-0.1)$; for the elderly adults' samples, velocities are respectively $3.5 \mathrm{~mm} / \mu \mathrm{s}(+/-0.2)$ and $1.9 \mathrm{~mm} / \mu \mathrm{s}(+/-0.09)$. The mean MOEdyn and the mean MOEsta for the children's samples are respectively $15.5 \mathrm{GPa}(+/-3.4)$ and $9.1 \mathrm{GPa}(+/-3.5)$; for the elderly adults' samples, they are respectively $16.7 \mathrm{GPa}(+/-1.9)$ and $5.8 \mathrm{GPa}(+/-2.1)$. MOEdyn, $v$ and MOEsta are in the same range for children's and elderly adults' bone without any statistical difference; a ranking correlation between MOEdyn and MOEsta is shown for the first time. 
1 Title: In vitro ultrasonic and mechanic characterization of the modulus of elasticity of

2 children cortical bone

3

$4 \quad$ Jean-Philippe Berteau

5 Laboratory of mechanics and acoustics (LMA) CNRS UPR 7051 Aix -Marseille University

6 Centrale Marseille, 31 chemin Joseph-Aiguier F-13402 Marseille cedex 20 France

7 Aix-Marseille University CNRS, ISM UMR 7287, 13288, Marseille cedex 9, France

8 Cécile Baron, Martine Pithioux, Franck Launay and Patrick Chabrand

9 Aix-Marseille University CNRS, ISM UMR 7287, 13288, Marseille cedex 9, France

10 Philippe Lasaygues

11 Laboratory of mechanics and acoustics (LMA) CNRS UPR 7051 Aix -Marseille University

12 Centrale Marseille, 31 chemin Joseph-Aiguier F-13402 Marseille cedex 20 France

Abbreviated title: Cortical bone elastic properties in children

Correspondence:

J-Ph. Berteau

Institute of Biomechanics, TUHH Hamburg University of Technology, Denickestrasse 15, 21073 Hamburg, Germany, Tel: +49 (0)40 42878 4376, Fax: +49 (0)40 42878 2996, e-mail:jph.berteau@gmail.com 
2 The assessment of elastic properties in children's cortical bone is a major challenge for 3 biomechanical engineering community, more widely for health care professionals. Even with 4 classical clinical modalities such as X-ray tomography, MRI, and/or echography, 5 inappropriate diagnosis can result from the lack of reference values for children bone. This 6 study provides values for elastic properties of cortical bone in children using ultrasonic and 7 mechanical measurements, and compares them with adult values. 17 fibula samples from 8 children (4 to 16 years old, mean age 10 years old +/- 4.5) were compared to 16 fibulae samples from elderly adults (more than 75 years old). First, the dynamic modulus of elasticity $\left(\mathrm{MOE}_{\mathrm{dyn}}\right)$ and Poisson's ratio (v) are evaluated via an ultrasonic method. Second, the static modulus of elasticity $\left(\mathrm{MOE}_{\text {sta }}\right)$ is estimated from a 3-point microbending test. The mean values of longitudinal and transverse wave velocities measured at $10 \mathrm{MHz}$ for the children's samples are respectively $3.2 \mathrm{~mm} / \mu \mathrm{s}(+/-0.5)$ and $1.8 \mathrm{~mm} / \mu \mathrm{s}(+/-0.1)$; for the elderly adults' samples, velocities are respectively $3.5 \mathrm{~mm} / \mu \mathrm{s}(+/-0.2)$ and $1.9 \mathrm{~mm} / \mu \mathrm{s}(+/-0.09)$. The mean $\mathrm{MOE}_{\mathrm{dyn}}$ and the mean $\mathrm{MOE}_{\text {sta }}$ for the children's samples are respectively $15.5 \mathrm{GPa}(+/-3.4)$ and 9.1 GPa (+/- 3.5); for the elderly adults’ samples, they are respectively $16.7 \mathrm{GPa}(+/-1.9)$ and 5.8 GPa (+/- 2.1). $\mathrm{MOE}_{\text {dyn }}, v$ and $\mathrm{MOE}_{\text {sta }}$ are in the same range for children's and elderly adults' bone without any statistical difference; a ranking correlation between $\mathrm{MOE}_{\mathrm{dyn}}$ and $\mathrm{MOE}_{\text {sta }}$ is shown for the first time.

Keywords: Ultrasonic wave velocities -Elastic properties-Pediatrics-Cortical bone 
3. Introduction

Cortical bone is an organic structure with mineral comprises approximately $80 \%$ of the human skeleton. Pathologies impacting human cortical bone quality include osteoporosis [1] in adults and osteopenia [2], Crohn's disease [3] or osteopetrosis [4] in children. In addition to its cost in terms of health, European estimates predict that the direct cost of osteoporotic fracture will reach 76.7 billion $€$ by 2050 due to demographic changes, notably the ageing of European populations [5]. A low bone mass in childhood is now recognized as a high risk factor for osteoporosis in later life [6] and authors consider the assessment of bone mineral status in children as a priority [7,8]. The Bone Mineral Density (BMD), which is one of the most gold standard parameters to assess mineral status, requires in the first intention, the use of the dual energy X-ray absorptiometry (DXA). The reference study [9] concerns only 7-17year-old children, and was conducted with a Hologic DXA scanner (Hologic Inc., Waltham, MA, USA), ruling out comparison with values obtained via other scanners. However, the pediatric evaluation of the BMD raises problems of interpretation when the size of the bone varies related to the statural age of the child. The BMD is not correlated with the bone microarchitecture, and several studies have shown the ability of ultrasound measurement to assess the quantity and the quality of the explored bone area (elasticity and structure) $[10,11]$.

There is a tremendous lack of data on young bone strength and mechanical behaviors: several papers $[12,13,14]$ report age-dependence for ultrasonic axial transmission data but, to our knowledge, the elastic properties of cortical bone in children have been quantitatively investigated by only two in vitro mechanical studies $[15,16]$, both using destructive tests on dry samples. In both cases, the experimental values for bone in children support the theoretical optimization hypothesis [17] of an increasing bone modulus of elasticity from neonate values to adult values, which is currently used in pediatric computational methods. All this would suggest the likelihood of lower ultrasonic wave velocities and modulus of 
1 elasticity in children compared to adults. Yet the findings of a recent study performed by our

2 team on rib cortical bone from teenagers with scoliosis [18] do not support that hypothesis.

3 Although our study concerned pathological bone, our conclusion was that the in vitro

$4 \quad$ ultrasonic wave velocities and the MOE values were close to the elderly adult values found in

5 the current literature. The lack of reference concerning normative pediatric ultrasonic wave

6 velocities and elastic properties of children's prevents the medical community from using the

7 diagnosis devices based on analytic model of ultrasound scattering dedicated to adult's

8 population (Quantitative ultrasound and echography). Consequently, the data collection and

9 the development of relevant models of bone growth is a critical need to investigate an effective device of diagnosis and to meet the needs expressed by the medical community.

The aim of this study was to obtain ultrasonic wave velocities, dynamic and static modulus of elasticity, and Poisson's ratio for cortical bone samples from children, and then to compare these results with elderly adult cortical bone samples. Our two-stage study proceeded first by performing experimental ultrasound measurements to assess ultrasonic wave velocities, dynamic modulus of elasticity $\left(\mathrm{MOE}_{\mathrm{dyn}}\right)$ and Poisson's ratio $(v)$ and second, via 3-point microbending tests, to assess static modulus of elasticity ( $\left.\mathrm{MOE}_{\text {sta }}\right)$.

\section{Materials and Methods}

Figure 1 is a diagrammatic representation of the method used.

\subsection{Samples}

In accordance with the stipulations of the French ethical committee, we studied cortical bone samples from Caucasian patients (4 to 16 years old, mean age 10 years old +/4.5) of the University Hospital in Marseille who required auto transplant surgery. Surgical waste bone, largely consisting of cortical bone from fibula diaphysis was studied; the selected population was composed of walking children not on drugs disturbing their bone metabolism. 
1 All auto transplant samples were excised from a non-pathological location in the fibula $5 \mathrm{~cm}$

2 above the ankle (figure 1). The elderly adult bone fibula samples were extracted from the same location as for the children's samples, but from cadavers (+ 75 YO) at Inserm U1033 and UMR-T 9406 Ifsttar/UCBL (Lyon, France) bone bank. Samples for study were obtained by cutting the waste fragments in parallelepipeds (plane and parallel surfaces) using a lowspeed diamond saw (Isomet 1000, Buehler; Lake Bluff, IL, USA). A total of 17 cortical bone parallelepipeds extracted from 8 children fibula samples were obtained and measured with a digital caliper. Great care was required due to the small size of the bone samples from the children: 15 to $35 \mathrm{~mm}$ long (bone axis direction), 10 to $20 \mathrm{~mm}$ wide and 2 to $3.5 \mathrm{~mm}$ deep (transverse directions). Sixteen elderly adult (+75 years old) bone samples excised from cadavers were similarly prepared. Each sample was designated (F or $\mathrm{M}$ for sex)-(age)-(F for fibula)-(number for each piece) and stored at $-20^{\circ} \mathrm{C}$ in phosphate buffered saline with less than 5 freezing cycles.

\subsection{Ultrasonic measurements}

We used an ultrasonic protocol specifically developed, as detailed in Pithioux et al. [19] and Loosvelt et Lasaygues [20], to process small and thin samples, and which has been validated on standard materials and animal and human adult bones. The ultrasonic bench [18] used consisted of a main arm carrying two linear stages. Each linear stage was carrying the end-rod transducer, and was moved linearly with increments of hundredths of millimeters. The parallelepiped bone sample to be tested was placed in the presumed geometrical center of the bench so that the maximum distance between the transducers and the center was $30 \mathrm{~mm}$. The surrounding fluid medium was water at a temperature of $18^{\circ}$.

The surrounding fluid medium was water at a temperature of $18^{\circ}$. Two focused broadband transducers (2R, figure2) at $10 \mathrm{MHz}$, (5 mm diameter, $6 \mathrm{~dB}$-bandwidth ranging 
1 from 9 to $13 \mathrm{MHz}$; Imasonic, Besançon, France), facing each other with their axes aligned,

2 were used to scan along transverse parallel directions through the sample (perpendicular to

3 the bone axis). The focal area $\left(\mathrm{X}_{\mathrm{a}} \times \mathrm{X}_{\mathrm{L}}\right.$, figure2) of the transducer was $3 \times 3 \mathrm{~mm}$ with a focus set (F, figure2) at $30 \mathrm{~mm}$. At this distance, the wave front was assumed to be plane, and the effect of the secondary lobes can be considered negligible. The wave reached the interface, also assumed to be plane at this scale, perpendicularly. Because the thickness of the samples ranged from 2 to $3.5 \mathrm{~mm}$, a nominal frequency of $10 \mathrm{MHz}$ was chosen, making the wavelength in water ten times greater than the sample thickness. Only propagation processes were taken into account and the ultrasonic wave attenuation was assumed to be weak. Longitudinal and transversal waves are excited when the incident sound wave strikes the bone surface under appropriate incident angles $\theta \mathrm{i}\left(\theta \mathrm{i} \in\left[0^{\circ}, 90^{\circ}\right]\right)$ and therefore only the time-offlight (TOF) of the waves was measured.

For each sample, thickness e was first calculated using the pulse-echo technique. TOFs of the propagating waves were determined in the reflection mode, from the left (respectively right) transducer to the left (respectively right) interface of the sample. The TOF measured between transducers without samples was used as reference. All measured thicknesses were compared to caliper measurements.

The velocities $V_{l}$, (respectively $V_{t}$ ) of the longitudinal (respectively transverse) waves in the samples were determined in the transmission mode using the equation (1):

$V_{l, t}=\frac{C_{\text {water }}}{\sqrt{1+C_{\text {water }} \frac{\Delta t}{\mathrm{e}}\left(C_{\text {water }} \frac{\Delta t}{\mathrm{e}}-2 \cos \theta i\right)}}$

$\mathrm{C}_{\text {water }}$ is the ultrasonic wave velocity in water, measured without bone sample, using the distance between both transducers and the TOF of the wave in between, e the thickness of the sample. $\theta \mathrm{i}$ is the incidence angle and for each incidence angle, $\Delta \mathrm{t}$ is the maximum of the cross-correlation between the first signal going through the zero stage with the sample, and 
1 the reference signal measured earlier without the sample.

2 When $\theta i$ is lower than the first critical angle $\theta c$, we consider that the wave velocity estimated

3 is the velocity of longitudinal waves $\left(\mathrm{V}_{\mathrm{l}}\right)$ and when $\theta i$ is greater than $\theta c$, we consider that the

4 wave velocity estimated is the velocity of transverse waves $\left(V_{t}\right)$. Each parameter was assessed

5 by performing the tests in triplicate. Given the density $(\rho)$, the transverse dynamic modulus of 6 elasticity $\mathrm{MOE}_{\mathrm{dyn}}$ and Poisson's ratio $v$ were calculated using the following equations (2 and 7 3) [21]' [19]:

$8 \quad M O E_{d y n}=\rho \frac{V_{t}^{2}\left(3 V_{l}^{2}-4 V_{t}^{2}\right)}{\left(V_{l}^{2}-V_{t}^{2}\right)}$

$9 \quad v=\frac{V_{t}^{2}-2 V_{t}^{2}}{2\left(V_{l}^{2}-V_{t}^{2}\right)}(3)$

The US protocol tested the transversal axis of each bone samples, consequently only the transversal dynamic modulus of elasticity is calculated here.

\subsection{Mechanical measurements}

We designed a 3-point microbending testing system specifically to deal with such small samples (figure 1), mounted on a Universal Testing Machine (Instron 5566A, Norwood, MA). To evaluate the cortical bone samples, a span-to-depth ratio of $16: 1$ is a general rule; but in small samples it cannot be achieved, the shortest sample tested here was $15 \mathrm{~mm}$ to guarantee that $85-90 \%$ of the flexure of the bone is due to bending [22] leading to a minimum span-to-depth ratio of $10: 1$ for all samples. The thinnest sample was $1.5 \mathrm{~mm}$ leading to a mean width-to-thickness ratio around 4, which corresponds to a shear factor of 0.833 [23]. Consequently, the number of samples from children was reduced to 12 and the number of elderly adult samples to 8 . A pre-force of $5 \mathrm{~N}$ was applied on the sample before testing until rupture. The displacement speed was $0.2 \mathrm{~mm} / \mathrm{min}$, close to static testing conditions; the test provided a force/displacement curve for each sample, which was transformed into a strain/stress curve from which the static modulus of elasticity, $\mathrm{MOE}_{\text {sta }}$, was estimated. 
1 The F3P protocol tested the longitudinal axis of each bone samples, consequently only the

2 longitudinal static modulus of elasticity is calculated here.

3

\subsection{Statistical Analysis}

The Shapiro-Wilk test was performed to evaluate the distribution of results, Student's t-test was performed for normal distribution and a Spearman correlation was performed for abnormal distribution. The significance level is $\mathrm{p}<0.05$. All data generated by the experimental setup were analyzed using Excel 2007 and Analyse-it (Microsoft, Redmond, WA, USA).

5. Results

All the experimental results are presented as mean values in SIU (signal interface unit) with $+/$ - standard deviation in brackets.

\subsection{Ultrasonic measurements}

Figure 3 shows the longitudinal and transverse wave velocities calculated for the 17 bone samples from children. The mean values of the longitudinal and transverse wave velocities measured at $10 \mathrm{MHz}$ for the children's bone samples are respectively $3.2 \mathrm{~mm} / \mu \mathrm{s}$ (+/- 0.5) and $1.8 \mathrm{~mm} / \mu \mathrm{s}(+/-0.1)$; for the elderly adults’ bone samples, values are respectively $3.5 \mathrm{~mm} / \mu \mathrm{s}(+/-0.2)$ and $1.9 \mathrm{~mm} / \mu \mathrm{s}(+/-0.09)$. The measurement uncertainty for ultrasonic wave velocity on our bench is estimated at $2.25 \%$. The mean density ( $\rho$ ) for each group is reported in table 1 , as are the deduced dynamic modulus of elasticity $\left(\mathrm{MOE}_{\mathrm{dyn}}\right)$ and the Poisson's ratio $(v)$. 
5.2 Mechanical measurements

The three-point microbending test provided a mean $\mathrm{MOE}_{\text {sta }}$ for each group, as shown in Table 1 . The measurement uncertainty for the cell-force is estimated at $0.23 \%$.

\subsection{Statistical analysis}

The ultrasonic measurements show no statistical difference between the bone from children and from elderly adults with respect to longitudinal wave velocities, transverse wave velocities, $\rho, \mathrm{MOE}_{\text {dyn }}$ and $v$ (Student's t-test, $\mathrm{p}>>0.05$ ) (Table1). The mechanical measurements show no statistical difference between the bone from children and from elderly adults with respect to mean $\mathrm{MOE}_{\text {sta }}$ (Student's t-test, $\mathrm{p}>>0.05$ ) (Table1). In the bone from children, the distribution of $\mathrm{MOE}_{\text {dyn }}$ values is normal (Shapiro-Wilk test; $\mathrm{W}=0: 96, \mathrm{p}=0: 81$ ) and the distribution of the $\mathrm{MOE}_{\text {sta }}$ values is abnormal (Shapiro-Wilk test; $\mathrm{W}=0: 88, \mathrm{p}=0: 08$ ). The $\mathrm{MOE}_{\mathrm{dyn}}$ measured by ultrasound and the $\mathrm{MOE}_{\text {sta }}$ measured by 3-point microbending test for the children are plotted in figure 4 with white circles. A Spearman rank correlation test between $\mathrm{MOE}_{\mathrm{dyn}}$ and $\mathrm{MOE}_{\text {sta }}$ for the children's bone shows a positive value $(\mathrm{R}=0.765, \mathrm{p}=$ $0.0014)$.

\section{Discussion}

The assessment of cortical bone mineral status in children via non-radiating and noninvasive techniques using ultrasound technics may well enhance diagnosis in pediatrics, but their successful use must rely on gold-standard reference values. The aim of the study was first to measure ultrasonic wave velocities $\left(V_{l}\right.$ and $\left.V_{t}\right)$ in children's cortical bone samples excised from the fibula from which to calculate the elastic properties ( $\left.\mathrm{MOE}_{\mathrm{dyn}}\right)$, then to experimentally obtain the elastic properties for the same samples via a mechanical test 
$1 \quad\left(\mathrm{MOE}_{\text {sta }}\right)$, and finally to compare these bone values from children with elderly adult's cortical

2 bone samples excised from the fibula bone values obtained via the same protocol. range of the acoustic experimental values generally found for adult cortical bone (between 2.7 and $3.8 \mathrm{~mm} / \mu \mathrm{s}$ [24] and between 3.5 and $3.9 \mathrm{~mm} / \mu \mathrm{s}$ [25]). Similarly, the mean $\mathrm{MOE}_{\mathrm{dyn}}$ and the mean $v$ (Table 1) are in the lower range of the acoustic experimental values generally found for adult cortical bone. $\mathrm{MOE}_{\mathrm{dyn}}$ values in the literature generally range between 18.5 GPa and $33.1 \mathrm{GPa}$ [25], most being roughly $20 \mathrm{GPa}[21,26]$, but these previous studies concerned femur bone and to our knowledge no values concerning the fibula are available.

The $v$ values generally range between 0.22 and 0.42 [27]. Nevertheless, our results are close to the ultrasonic wave velocities already obtained with cortical bone from rib cortical samples of scoliotic teenagers (15 and 17 years old) using the same ultrasonic bench (respectively 3.2 $\mathrm{mm} / \mu \mathrm{s}$ and $1.7 \mathrm{~mm} / \mu \mathrm{s}$ for $\mathrm{V}_{\mathrm{l}}$ and $\mathrm{V}_{\mathrm{t}}$ ) [18]. Similarly, the mean $\mathrm{MOE}_{\mathrm{dyn}}$ and the mean $v$ found in that study (respectively $14.9 \mathrm{GPa}$ and 0.26 ) are in the same range as ours. The elasticity of cortical bone is largely dependent on its mineral constituents [28], and major changes in elasticity properties and mineral quality of physiological cortical bone have been quantified in ageing [29], or in adulthood [30]. However, little data is available on bone quality in childhood, so our findings here make a useful contribution to the literature.

When we compared the ultrasonic measurement results for the children with those for the elderly adults (+75YO), we found no statistical difference. This finding contradicts the theoretical optimization hypothesis [17] of stiffer bones in adults compared to children, which is currently used in computational models. Interestingly, Drozdzowska et al. [31] in their in vivo study found the speed of sound (SOS) evaluated at the phalanx roughly the same for children around 10 years old and people aged 70-80. The authors conclude that the SOS at the phalanx increases linearly to a maximum value reached at around 25 years old, and then the 
1 values decrease more slowly until the age of 80 . Given the age of our population (4-16 YO for

2 children and +75 YO for elderly adults), our in vitro results support their in vivo evaluation.

3 Moreover, similarly to Drozdzowska et al., an in vivo study [32] using peripheral quantitative

4 computed tomography showed that bone mineral mass in a 1-mm-thick slice of the cortical

5 bone cross-section of the proximal radius increased from childhood (6 years old) to adulthood

6 (up to 40 years old). Clearly, the impact of age on bone mineral status could be explored more thoroughly if samples from younger adults were included. However, for an in vitro study on fresh bone, it is extremely difficult to obtain a wide range of donor ages. Furthermore, one limitation exists in the preparation process even if all the samples have been prepared in the same way, the children samples were fresh and the elderly population samples came from cadavers, however to our knowledge and up to date, no impact of that difference has been shown on ultrasound propagation. The main difference lies in the time of freezing which is hard to set with bone from several origins, but frozen bones can safely be used for mechanical testing, at least for storage periods of up to one year [33] which is consistent with our process. One of the critical points concerning acoustical measurements is the sensitivity of $\mathrm{V}_{\mathrm{l}}$ and $V_{t}$ to the ratio e/ $\Delta t$ (equation 1 ). In figure 5 , we plot the longitudinal wave velocity measured in bone at normal incidence as a function of e/ $\Delta \mathrm{t}$ for a given wave propagation velocity in water $C_{\text {water }}=1.48 \mathrm{~mm} / \mu \mathrm{s}$. The black crosses represent the theoretical $V_{l}$ values obtained from equation (1) for the experimental values of e/ $\Delta \mathrm{t}$. It is noteworthy that in a range between 1 and $2 \mathrm{~mm} / \mu$ s the sensitivity of $\mathrm{V}_{\mathrm{l}}$ is very high, whereas it becomes more acceptable over $2 \mathrm{~mm} / \mu \mathrm{s}$. The critical value corresponds to $\mathrm{C}_{\text {water, }}$ and if we look at the accuracy of $\mathrm{V}_{\mathrm{l}}$ estimation versus the error in $\mathrm{e} / \Delta \mathrm{t}$ for different $\mathrm{e}=\Delta \mathrm{t}$ ratios between 2 and $5 \mathrm{~mm} / \mu \mathrm{s}$ (corresponding to experimental range), it appears that the sensitivity of $V_{l}$ estimation decreases when the ratio increases. For example, an error of $10 \%$ in the estimation of a ratio around 2 induces an error of $16 \%$ in the estimation of $\mathrm{V}_{\mathrm{l}}$; and an error of $6 \%$ in the estimation 
1 of a ratio around 5 induces an error of $7 \%$ in the estimation of $V_{l}$. This example highlights one

2 of the limitations of the ultrasonic method, based on the pulse-echo mode. Research is

3 underway to tackle these limitations, and new ultrasonic measurement approaches and novel

4 signal-processing methods are currently being investigated [20]. Theory suggests another

5 issue concerning acoustical measurement, which is that SOS is influenced by the elasticity of

6 bone as well as bone mass density; but, measured according to the Archimedes' principle here

7 (Table 1), the bone mass density $(\rho)$ of cortical bone from fibula is in the usual range of 8 literature values.

The mechanical measurements performed here found the mean $\mathrm{MOE}_{\text {sta }}$ of the children's bone samples to be in the typical range of human cortical bone values obtained from three-point bending tests (between $8.6(+/-1,5)$ GPa [34] and $12.5 \mathrm{GPa}$ [35]). Concerning the comparison with the first study of children bone [15], using samples extracted from the mid-shaft of the femur (eighteen subjects with age range: 2 to 48 years old), it showed that the bone specimens taken from children were weaker and less stiff than those taken from adults. The second [16], with samples extracted from the top part of the femur diaphysis (12 children from 4 to 15 years old and 12 adults from 22 to 61), showed that bone from children and adults differed in cortical strength and stiffness, depending on ash density, although the compressive yield strain was the same. Both studies found a mechanical difference between children's and adults' bone with regard to stiffness, but the findings of both should be taken with caution. The first tested bone from cadavers, with insufficient samples to provide statistics on differences between children and adults for the elasticity parameters. The second studied bone samples close to cancer locations, which cannot be considered physiological tissue. Here, we didn't find any statistic difference concerning static modulus of elasticity but the span-to- depth ratio of 10:1 is not theoretically adequate to assess the MOE of bone material. Indeed, the contribution of shear deformation cannot be 
neglected, and consequently the $\mathrm{MOE}_{\text {sta }}$ evaluated in this study may be influenced by the dimensions of the samples and may lead to an underestimation of the MOE of cortical bone. However, a recent study [36] aiming at design and validate bending test method for characterization of miniature pediatric cortical bone specimens showed that a span to depth aspect ratio (5:6) provided reasonable results for both Young's modulus and flexural strength in bovine bone; this aspect ratio is not consistent with the general rule admitted. Nevertheless, since all the samples tested here showed the same span-to-depth ratio, we are able to compare results for the children with those for the elderly adults. Comparison of the children's $\mathrm{MOE}_{\text {sta }}$ with the elderly adults' $\mathrm{MOE}_{\text {sta }}$ obtained via mechanical tests shows no statistical difference in the Student T-test (Table 1); this finding contrasts with the literature $[15,16]$. One explanation of this absence of statistical difference may be the nature of the bone tested. Fibula ossification commences in the lower end in the second year; in vivo, DeSouza et al. [37] and El Haj et al. [38] pointed out the key role of mechanical stimulation in healing, remodeling and regeneration of bone. Even though the fibula bears relatively little weight in comparison with the tibia, walking may well stimulate the mineralization process of the bottom part of the fibula more strongly than other bones in the skeleton. However, the fibula being the preferred location for cortical bone auto transplants, we were unable to obtain other fresh bone.

Ultrasound offers two advantages over static measurements: i) it is a non-destructive tool; ii) it can be performed in vivo. However, the literature on biological tissue characterization shows that values obtained for static and dynamic elastic moduli differ. The values of the modulus of elasticity obtained through the ultrasonic method are usually higher than those found with static deflection. This difference exists not only for bone but also for biological material like wood. In wood, Halabe et al. [39] explained the difference between the two moduli of elasticity as follows: wood is a viscous, elastic and highly impact-absorbent 
material, so its behavior depends on the duration of the excitation: the shorter the excitation is (ultrasound excitation), the stiffer the material appears. Here, due to the small size of our samples and the difficulty of obtaining usable surgical waste, we could only assess transversal elasticity (perpendicularly to bone axis) via acoustical measurements and longitudinal elasticity via mechanical measurements. However, adult cortical and trabecular bone are orthotropic [40], so it might be assumed that children's cortical bone is also an anisotropic tissue. Consequently, future studies on children's bone should also explore the other axes of the bone for a more thorough comparison of static and dynamic MOE. Nevertheless, the values for both $\mathrm{MOE}_{\mathrm{dyn}}$ and $\mathrm{MOE}_{\text {sta }}$ reported here (Table 1) are consistent with those usually reported in the literature [41], and a Spearman ranking correlation between the two moduli of elasticity is obtained (Figure 4). To our knowledge, the correlation obtained here is the first to establish a strong link between dynamic and static moduli for human cortical bone in children, or even for human cortical bone in general. In a recent study [41] of women’s cortical bone, the authors obtained only a marginal negative correlation between $\mathrm{MOE}_{\mathrm{dyn}}$ (ultrasonic measurement with guided waves) and $\mathrm{MOE}_{\text {sta }}$ (three-point bending). Investigating a linear correlation between $\mathrm{MOE}_{\text {dyn }}$ and $\mathrm{MOE}_{\text {sta }}$ and exploring the hypothesis of anisotropy of children's bone will require further experiments with more and thinner samples, a challenging undertaking.

In conclusion, this study contributes a new set of ultrasonic wave velocities and elasticity values for children's cortical bone. Furthermore, for the first time it provides a ranking correlation between children's cortical bone elasticity values obtained using two different approaches (acoustical and mechanical measurements). Finally, the comparison performed here with elderly adults' bone does not support the theoretical optimization hypothesis [17] of an increasing bone modulus of elasticity values from neonate to adult which is currently used in pediatric computational methods. 
2 This study was based on research supported by the French National Research Agency

7. Acknowledgements

(BioGMID Program ANR under Grant n¹83692 and MALICE Program ANR under Grant $\left.\mathrm{n}^{\circ} \mathrm{BS} 09-032\right)$. We thank the Timone Hospital surgery team and the donors or their legal guardians who gave informed written consent to providing their tissues for investigation, in accordance with the French Code of Public Health (Code de la Santé Publique Française) and approved by the Committee for the Protection of Persons. This work benefited from the very fruitful help of Georges Boivin, and Héléne Follet from INSERM U1033 and from UMR-T 9406 Ifsttar/UCBL. We thank Marjorie Sweetko for English language revision.

\section{Conflict of Interest statement}

There is no conflict of interest.

\section{References}

1. Mc Donnell P, Mc Hugh PE, O’mahoney D. Vertebral osteoporosis and trabecular bone quality. Annals of biomedical engineering. 2007;35(2):170-89.

2. Mehlman CT, Shepherd MA, Norris CS, McCourt JB. Diagnosis and Treatment of Osteopenic Fractures in Children. Current Osteoporosis Reports. 2012 oct $17 ; 10(4): 317-321$.

3. Walters TD. IBD: Is measuring bone age in children with Crohn's disease useful? Nat Rev Gastroenterol Hepatol. 2012 nov;9(11):620-622.

4. Engiz O, Kara S, Bagrul D, Lahr G, Alioglu B, Arikan I, Bilge YD. Infantile malignant osteopetrosis: a rare cause of neonatal hypocalcemia. Journal of Pediatric Endocrinology and Metabolism [Internet]. 2012 janv 1 [cité 2013 janv 22];25(11-12). 
1 5. Kanis JA, Cooper C, Hiligsmann M, Rabenda V, Reginster JY, Rizzoli R. Partial adherence: a new perspective on health economic assessment in osteoporosis. Osteoporosis international. 2011;22(10):2565-73.

6. Javaid MK, Cooper C. Prenatal and childhood influences on osteoporosis. Best Pract. Res. Clin. Endocrinol. Metab. 2002 juin;16(2):349-367.

7. Bachrach LK. Osteoporosis in children: still a diagnostic challenge. J. Clin. Endocrinol. Metab. 2007 juin;92(6):2030-2032.

8. Zhang C, Liu Z, Klein GL. Overview of pediatric bone problems and related osteoporosis. Journal of musculoskeletal \& neuronal interactions. 2012;12(3):174.

9. Kalkwarf HJ, Zemel BS, Gilsanz V, Lappe JM, Horlick M, Oberfield S, Mahboubi S, Fan B, Frederick MM, Winer K, Shepherd JA. The bone mineral density in childhood study: bone mineral content and density according to age, sex, and race. J. Clin. Endocrinol. Metab. 2007 juin;92(6):2087-2099.

10. Laugier P. Instrumentation for in vivo ultrasonic characterization of bone strength. Ultrasonics, Ferroelectrics and Frequency Control, IEEE Transactions on. 2008;55(6):1179-96.

11. Cretin D, Suetoshi R, Uodome A, Ogawa S, Miyabe S, Nakano T. Assessment of cortical bone density and anisotropy in human femur using ultrasound and x-ray. The Journal of the Acoustical Society of America. 2008;123(5):3785.

12. Weiss M, Ben-Shlomo AB, Hagag P, Rapoport M. Reference database for bone speed of sound measurement by a novel quantitative multi-site ultrasound device. Osteoporos Int. 2000;11(8):688-696.

13. Talmant M, Kolta S, Roux C, Haguenauer D, Vedel I, Cassou B, Bossy E, Laugier P. In vivo performance evaluation of bi-directional ultrasonic axial transmission for cortical bone assessment. Ultrasound Med Biol. 2009 juin;35(6):912-919. 
14. Kilappa V, Moilanen P, Xu L, Nicholson PHF, Timonen J, Cheng S. Low-frequency axial ultrasound velocity correlates with bone mineral density and cortical thickness in the radius and tibia in pre- and postmenopausal women. Osteoporos Int. 2011 avr;22(4):1103-1113.

15. Currey JD. Changes in the impact energy absorption of bone with age. Journal of biomechanics. 1979;12(6):459-69.

16. Öhman C, Baleani M, Pani C, Taddei F, Alberghini M, Viceconti M, Manfrini M. Compressive behaviour of child and adult cortical bone. Bone. 2011;49(4):769-76.

17. Child Occupant Protection Symposium, Society of Automotive Engineers, Association for the Advancement of Automotive Medicine, International Research Council on the Biomechanics of Impact, Stapp Car Crash Conference. Child Occupant Protection 2nd Symposium proceedings. Society of Automobile Engineers; 1997.

18. Berteau J-P, Pithioux M, Follet H, Guivier-Curien C, Lasaygues P, Chabrand P. Computed tomography, histological and ultrasonic measurements of adolescent scoliotic rib hump geometrical and material properties. J Biomech. 2012 sept 21;45(14):2467-2471.

19. Pithioux M, Lasaygues $\mathrm{P}$, Chabrand P. An alternative ultrasonic method for measuring the elastic properties of cortical bone. Journal of biomechanics. 2002;35(7):961-8.

20. Loosvelt M, Lasaygues P. A Wavelet-Based Processing method for simultaneously determining ultrasonic velocity and material thickness. Ultrasonics. 2011 avr;51(3):325-339.

21. Ashman RB, Cowin SC, Van Buskirk WC, Rice JC. A continuous wave technique for the measurement of the elastic properties of cortical bone. Journal of Biomechanics. 1984 janv;17(5):349-361. 
22. Turner $\mathrm{CH}$, Burr DB. Basic biomechanical measurements of bone: A tutorial. Bone. 1993 juill;14(4):595-608.

23. Brancheriau L. Influence of cross section dimensions on Timoshenko's shear factor Application to wooden beams in free-free flexural vibration. Annals of Forest Science. 2006 avr 4;63(3):319-321.

24. Yoon HS, Katz JL. Ultrasonic wave propagation in human cortical bone--II. Measurements of elastic properties and microhardness. J Biomech. 1976;9(7):459-464.

25. Bensamoun S, Gherbezza J-M, De Belleval J-F, Ho Ba Tho M-C. Transmission scanning acoustic imaging of human cortical bone and relation with the microstructure. Clin Biomech (Bristol, Avon). 2004 juill;19(6):639-647.

26. Hobatho MC, Rho JY, Ashman RB. Anatomical variation of human cancellous bone mechanical properties in vitro. Stud Health Technol Inform. 1997;40:157-173.

27. Rohrbach D, Lakshmanan S, Peyrin F, Langer M, Gerisch A, Grimal Q, Laugier P, Raum K. Spatial distribution of tissue level properties in a human femoral cortical bone. J Biomech. 2012 août 31;45(13):2264-2270.

28. Bala Y, Depalle B, Douillard T, Meille S, Clément P, Follet H, Chevalier J, Boivin G. Respective roles of organic and mineral components of human cortical bone matrix in micromechanical behavior: An instrumented indentation study. Journal of the Mechanical Behavior of Biomedical Materials. 2011 oct;4(7):1473-1482.

29. Wang X, Puram S. The Toughness of Cortical Bone and Its Relationship with Age. Annals of Biomedical Engineering. 2004 janv;32(1):123-135.

30. Wang X, Li X, Shen X, Agrawal CM. Age-related changes of noncalcified collagen in human cortical bone. Annals of Biomedical Engineering. 2003;31(11):1365-71. 
31. Drozdzowska B, Pluskiewicz W. Skeletal status in males aged 7-80 years assessed by quantitative ultrasound at the hand phalanges. Osteoporos Int. 2003 juin;14(4):295-300.

32. Schoenau E, Neu CM, Rauch F, Manz F. The development of bone strength at the proximal radius during childhood and adolescence. Journal of Clinical Endocrinology \& Metabolism. 2001;86(2):613-8.

33. Van Haaren EH, Van der Zwaard BC, Van der Veen AJ, Heyligers IC, Wuisman PI, Smit TH. Effect of long-term preservation on the mechanical properties of cortical bone in goats. Acta Orthopaedica. 2008 janv;79(5):708-716.

34. Cuppone M, Seedhom BB, Berry E, Ostell AE. The longitudinal Young's modulus of cortical bone in the midshaft of human femur and its correlation with CT scanning data. Calcif. Tissue Int. 2004 mars;74(3):302-309.

35. Lotz JC, Gerhart TN, Hayes WC. Mechanical properties of metaphyseal bone in the proximal femur. J Biomech. 1991;24(5):317-329.

36. Albert CI, Jameson J, Harris G. Design and validation of bending test method for characterization of miniature pediatric cortical bone specimens. Proceedings of the Institution of Mechanical Engineers, Part H: Journal of Engineering in Medicine. 2012 oct 26;227(2):105-113.

37. De Souza RL, Matsuura M, Eckstein F, Rawlinson SCF, Lanyon LE, Pitsillides AA. Non-invasive axial loading of mouse tibiae increases cortical bone formation and modifies trabecular organization: A new model to study cortical and cancellous compartments in a single loaded element. Bone. 2005 déc;37(6):810-818.

38. El Haj AJ, Minter SL, Rawlinson SC, Suswillo R, Lanyon LE. Cellular responses to mechanical loading in vitro. J. Bone Miner. Res. 1990 sept;5(9):923-932. 
1 39. Halabe UB, GangaRao HVS, Petro SH, Hota VR. Assessment of defects and mechanical properties of wood members using ultrasonic frequency analysis. Mater. Eval. 1996 févr;54(2):314-322.

40. Rho J-Y. An ultrasonic method for measuring the elastic properties of human tibial cortical and cancellous bone. Ultrasonics. 1996 déc;34(8):777-783.

41. Grimal Q, Haupert S, Mitton D, Vastel L, Laugier P. Assessment of cortical bone elasticity and strength: mechanical testing and ultrasound provide complementary data. Med Eng Phys. 2009 nov;31(9):1140-1147.

9 


\begin{tabular}{|c|c|c|c|c|}
\hline & $\rho\left(\mathrm{kg} / \mathrm{m}^{3}\right)$ & $\mathrm{MOE}_{\text {dyn }}(\mathrm{GPa})$ & $v$ & $\mathrm{MOE}_{\text {sta }}(\mathrm{GPa})$ \\
\hline Children & $1.84 \pm 1.12$ & $15.5 \pm 3.4$ & $0.24 \pm 0.08$ & $9.1 \pm 3.5$ \\
\hline Elderly adults & $1.73 \pm 0.08$ & $16.7 \pm 1.9$ & $0.27 \pm 0.05$ & $5.8 \pm 2.1$ \\
\hline Student T-test & $\mathrm{P}>>0.05$ & $\mathrm{P}>>0.05$ & $\mathrm{P}>>0.05$ & $\mathrm{P}>>0.05$ \\
\hline
\end{tabular}

Table 1: Mean values (+/- SD) of density $\rho, \mathrm{MOE}_{\text {sta }}, v$ and $\mathrm{MOE}_{\mathrm{dyn}}$ for the children's (mean

3 age : 10 years old +/- 4.5) and the elderly adults' bone samples (+ 75 years old)

Figure 1: a. samples preparation: the waste fragment from auto transplant which was selected to prepare one of the children's cortical bone samples tested, b. plan of the special ultrasonic bench to assess acoustic elastic properties, in a water tank the bone sample is located between transducers ( T1 and T2), all of them mounted on 3D rotational axis c. picture of one sample during mechanical measurements via the three-point microbending setup.

Figure2 : Aperture of the $10 \mathrm{MHz}$-transducer (Imasonic ${ }^{\circledR}$ ); $\mathrm{R}$ and $\mathrm{H}$ are respectively the radius and the length of the transducer; ; F is the focusing distance; Xa and XL are respectively the focal length and the slice thickness.

Figure 3: Longitudinal (black crosses) and transverse (black dots) wave velocities measured at $10 \mathrm{MHz}$ for children’s bone samples

Figure 4: $\mathrm{MOE}_{\mathrm{dyn}}$ measured by ultrasound and $\mathrm{MOE}_{\text {sta }}$ measured by three-point bending test on children’s bone (white circles)

Figure 5: longitudinal wave velocity measured in bone at normal incidence as a function of $\mathrm{e} / \Delta \mathrm{t}$ for a given wave propagation velocity in water $\mathrm{C}_{\text {water }}=1.48 \mathrm{~mm} / \mu \mathrm{s}$. The black crosses represent the theoretical $V_{l}$ values obtained from equation (1) for the experimental values of $\mathrm{e} / \Delta \mathrm{t}$. 
Figure 1

Click here to download high resolution image
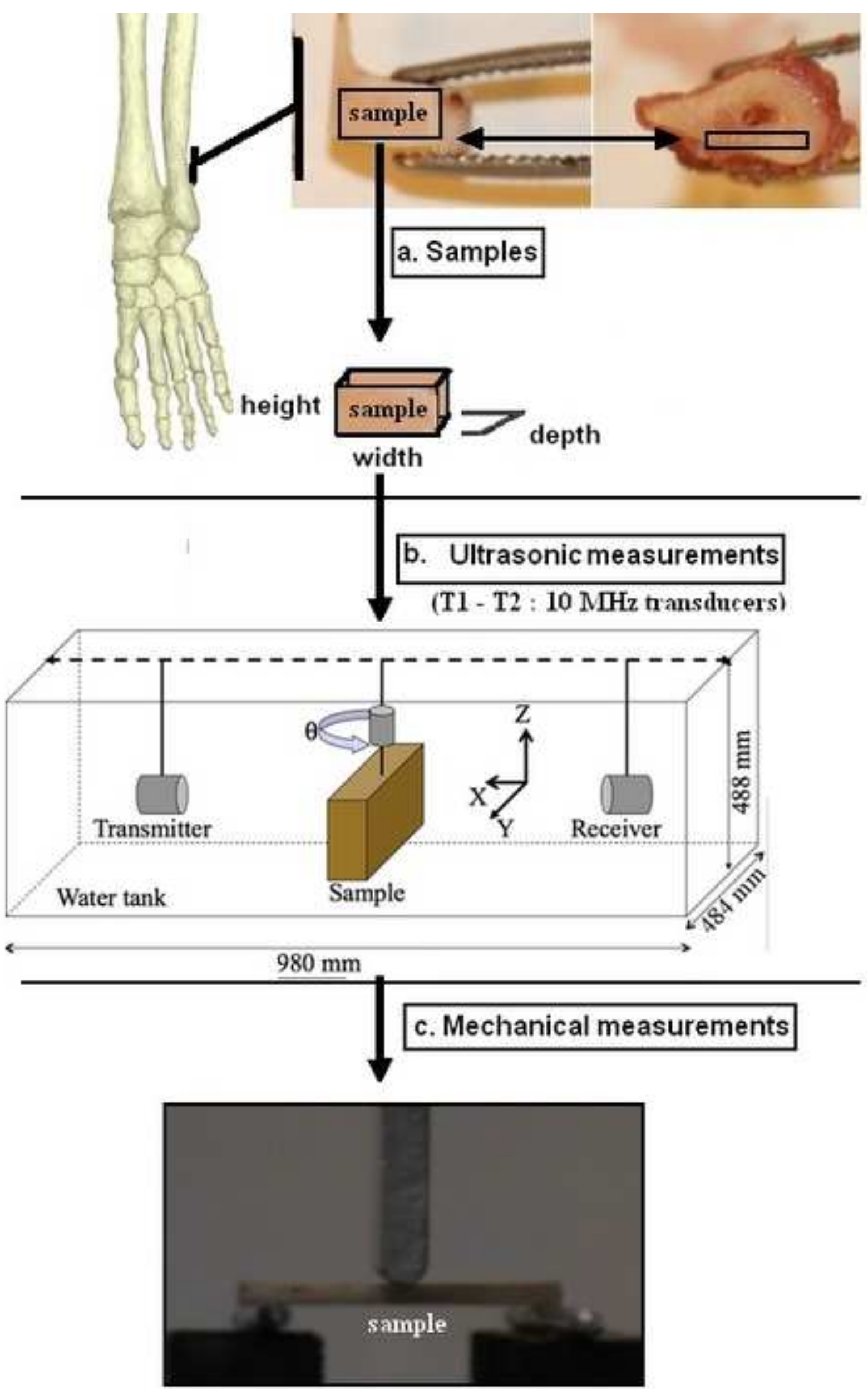
Click here to download high resolution image

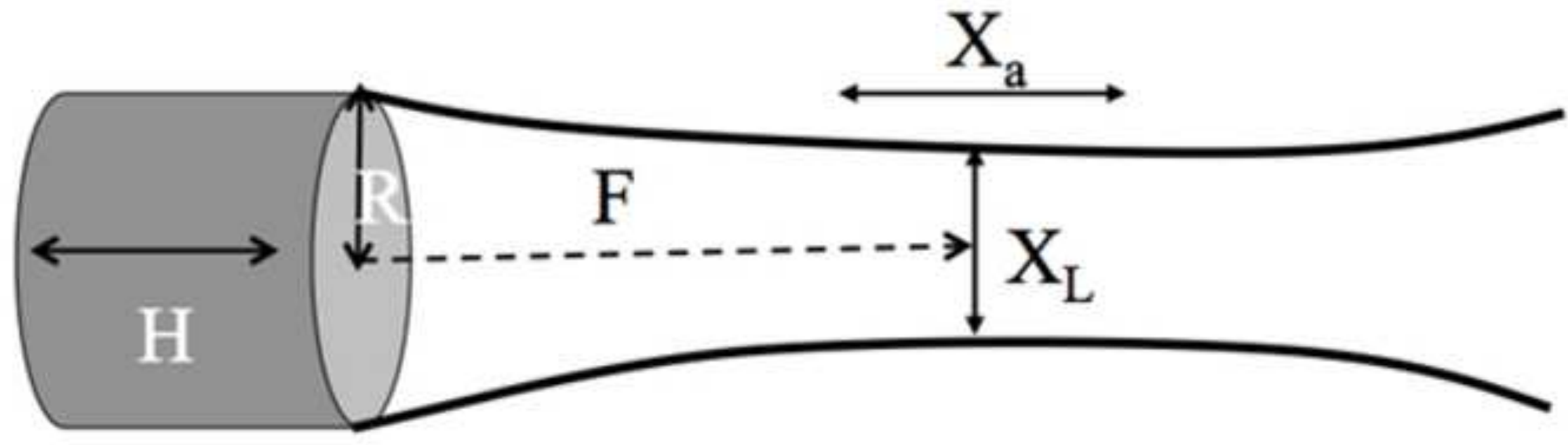




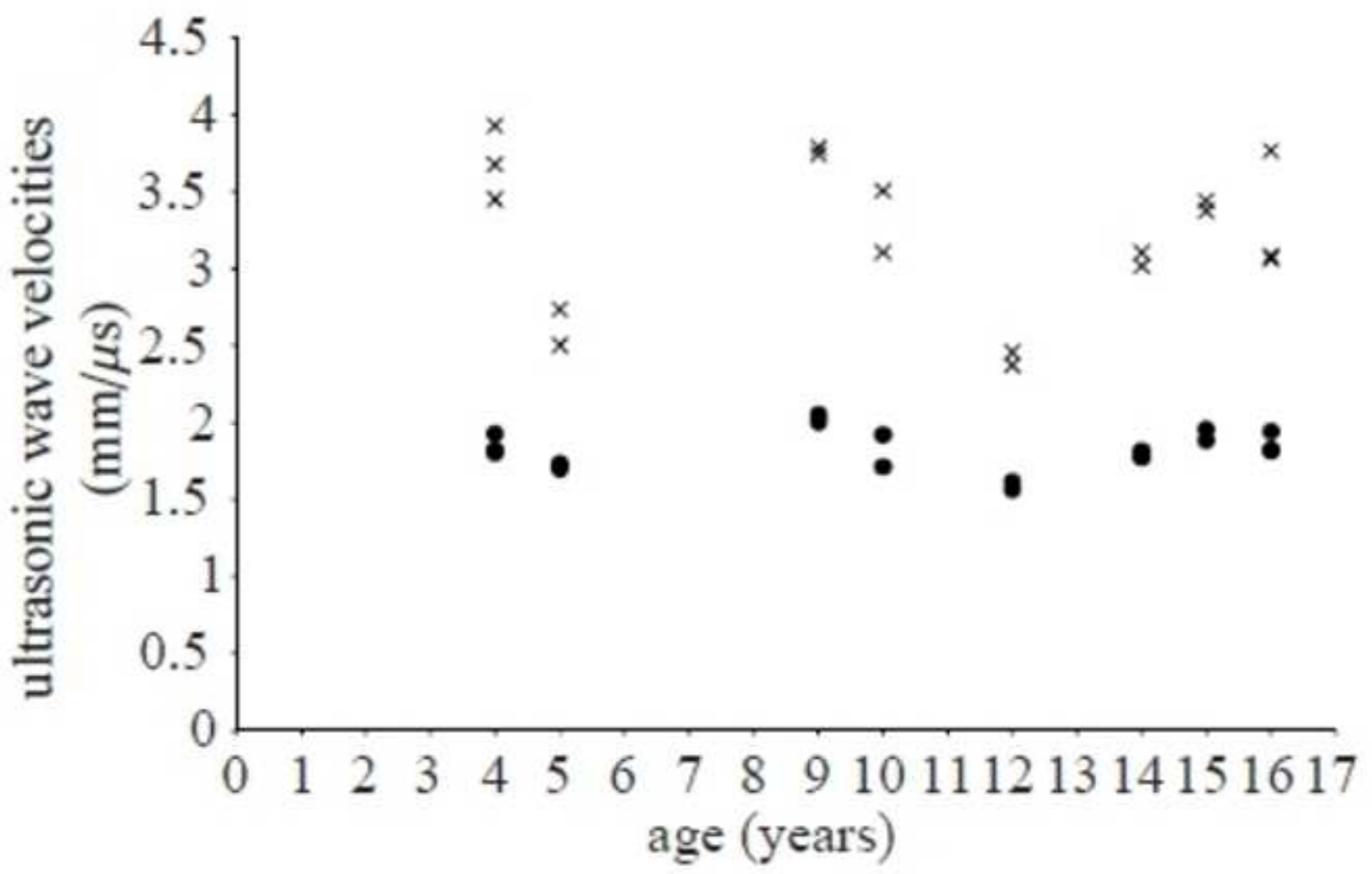

age (years) 
Click here to download high resolution image

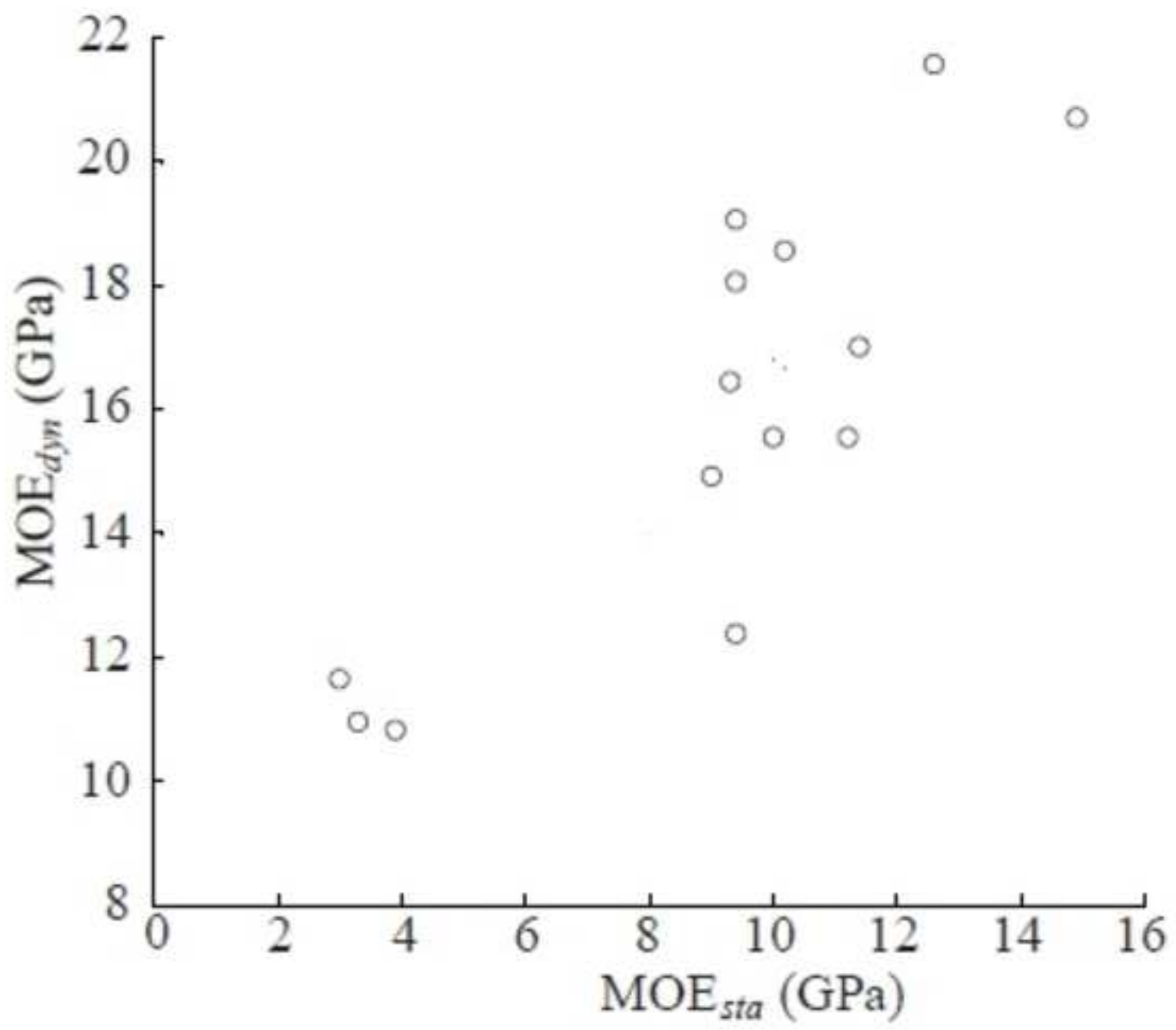




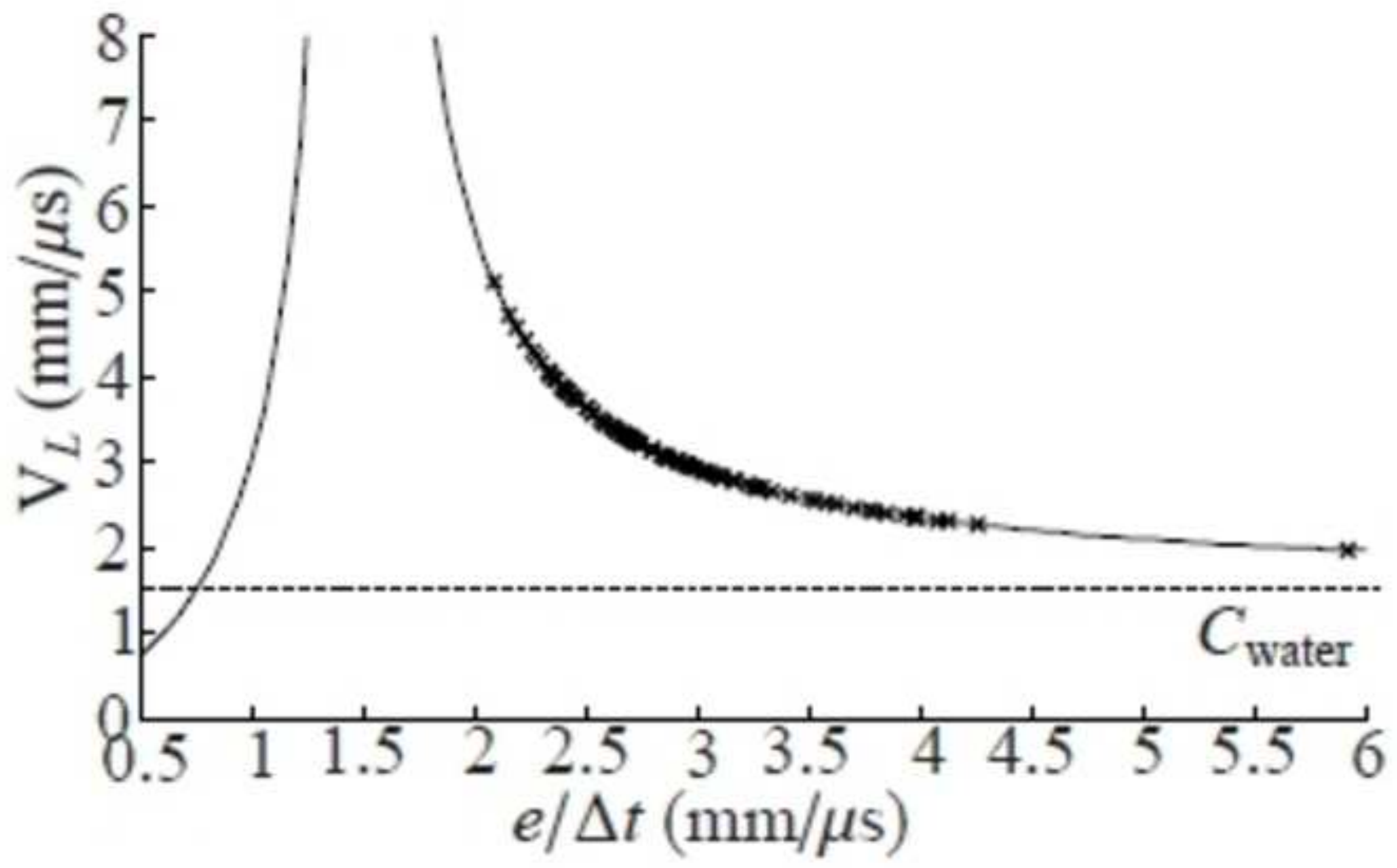




\section{Highlights}

- The mean values of longitudinal and transverse wave velocities for children's bone are respectively $3.2 \mathrm{~mm} / \mu \mathrm{s} \mathrm{(+/-} 0.5)$ and $1.8 \mathrm{~mm} / \mu \mathrm{s} \mathrm{(+/-} 0.1)$.

- Dynamic moduli of elasticity are in the same range for children's and elderly adults' bone without any statistical difference.

- A ranking correlation between dynamic modulus of elasticity and static modulus of elasticity is shown for children cortical bone samples. 